\title{
PENERAPAN WEB SERVICE DAN FIREBASE NOTIFICATION PADA PENGEMBANGAN APLIKASI GERAKAN NASI BUNGKUS JEMBER BERBASIS ANDROID
}

\author{
Yogiswara $^{1}$, Dimas Rayi Astriyanto ${ }^{2}$ \\ ${ }^{1,2}$ Teknologi informasi, ${ }^{3}$ Politeknik Negeri Jember \\ 1yogis@polije.ac.id, ${ }^{2}$ dimasrayi@gmail.com
}

\begin{abstract}
Abstrak
Aplikasi gerakan nasi bungkus (ganasbung) jember merupakan sebuah aplikasi yang dibutuhkan oleh salah satu komunitas sosial di Jember, aplikasi ini bertujuan membantu komunitas tersebut dalam proses penyebaran nasi bungkus dan pelayanan kepada donatur dalam memberikan donasi ke komunitas serta proses koordinasi antar anggota komunitas untuk penjemputan donasi. Penelitian ini berupa metode pengembangan aplikasi berbasis android dengan pengelolaan data terpusat yang difokuskan pada penerapan penggunaan teknologi web service dan integrasi firebase cloud system push notifikasi pada fitur notifikasi aplikasi tersebut. Metode pengujian yang dilakukan yaitu dengan menggunakan pengujian blackbox testing. Dapat disimpulkan dari penelitian ini bahwa penerapan web service dan fasilitas push notifikasi dalam pengembangan aplikasi berbasis android dapat mempermudah pengguna dalam memahami aplikasi tersebut.
\end{abstract}

Kata kunci: android, firebase, notifikasi, web service

\subsection{Pendahuluan}

Komunitas Gerakan Nasi Bungkus Jember atau yang biasa disebut Ganasbung Jember merupakan salah satu komunitas sosial yang beranggotakan para pemuda-pemudi Jember yang memiliki rasa kepedulian terhadap sesama. Komunitas ini memiliki misi membagikan kebahagiaan kepada sesamanya yang kurang beruntung dengan sebungkus nasi.

Komunitas ini memiliki donatur yang tersebar di seluruh daerah kota Jember. Kehadiran donatur tentu sangat membantu keberhasilan misi komunitas ini. Tak sedikit donatur yang rela menyisihkan sebagian hartanya untuk membantu keberlangsungan acara rutin Komunitas Gerakan Nasi Bungkus Jember ini, namun, tak sedikit pula donatur yang kebingungan untuk berdonasi di Komunitas Gerakan Nasi Bungkus Jember ini. Ketidaktahuan donatur akan contact person dari koordinatur komunitas ini, dan rumitnya proses koordinasi para anggota komunitas ini untuk menjemput donasi yang diberikan oleh donatur menjadi salah satu masalah yang dihadapi donatur ketika ingin berdonasi. Alhasil, tak sedikit donatur yang mengurungkan niatnya untuk mendonasikan sebagian hartanya di Komunitas Gerakan Nasi Bungkus Jember.

Berdasarkan kondisi tersebut Komunitas Gerakan Nasi Bungkus Jember memerlukan suatu aplikasi berbasis mobile yang memberi kemudahan kepada para donatur untuk berdonasi di komunitas ini, dan juga untuk membantu membantu proses koordinasi para anggota komunitas ini untuk menjemput donasi yang diberikan oleh para donatur, sehingga makin banyak donatur yang berdonasi di komunitas ini dan tentunya komunitas ini juga dapat membantu saudara kita yang kurang beruntung lebih banyak lagi.

\subsection{Tinjauan Pustaka \\ 2.1 Android}

Android merupakan sistem operasi yang digunakan untuk perangkat mobile berbasis Linux. Pada awalnya sistem operasi ini dikembangkan oleh Android.Inc, yang kemudian dibeli oleh Google pada tahun 2005. Android mengembangkan usaha pada tahun 2007 dibentuklah Open Handset Alliance (OHA), sebuah konsorsium dari beberapa perusahaan, yaitu Texas Instrument, Broadcom Corporation, Google, HTC, Intel, LG, Marvell Technology Group, Motorola, Nvidia, Qualcom, Samsung Electronics, Sprint Nextel, dan T-Mobile dengan tujuan untuk mengembangkan standar terbuka untuk perangkat mobile Smartphone

Sistem operasi Android memilki Fitur-fitur diantaranya:

1) Framework aplikasi : memungkinkan penggunaan dan pemindahan dari komponen yang tersedia.

2) Dalvik virtual machine : virtual machine yang dioptimalkan untuk perangkat mobile.

3) Grafik : grafik 2D dan grafik 3D yang didasarkan ada library OpenGL.

4) SQLite : untuk penyimpanan data.

5) Mendukung media : audio, video, dan berbagai format gambar (MPEG4, H.264, MP3, AAC, AMR, JPG, PNG, GIF).

6) Komunikasi data : GSM, Bluetooth, EDGE, 3G and WIFI. 
7) Kamera, Global Positioning System (GPS), Compass, dan Acceleratometer.

8) Lingkungan pengembangan aplikasi Android, termasuk emulator, peralatan debugging, dan plugin untuk Eclipse IDE (Hermawan, 2010).

Sistem operasi Android dibangun berdasarkan kernel Linux dan memiliki arsitektur sesuai dengan Gambar 1.

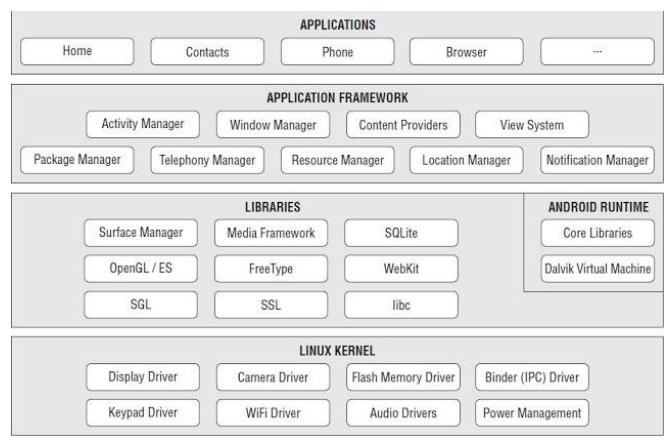

Gambar 1. Arsitektur Android

\subsection{Java}

Java adalah bahasa pemrograman yang dapat membuat seluruh bentuk aplikasi, desktop, web, mobile dan lainnya, sebagaimana dibuat dengan menggunakan bahasa pemrograman konvensional yang lain. Bahasa Pemrograman Java ini berorientasi objek (OOP-Object Oriented Programming), dan dapat dijalankan pada berbagai platform sistem operasi. Perkembangan Java tidak hanya terfokus pada satu sistem operasi, tetapi dikembangkan untuk berbagai sistem operasi dan bersifat open source.

Bahasa ini banyak mengadopsi sintaksis yang terdapat pada $\mathrm{C}$ dan $\mathrm{C}++$ namun dengan sintaksis model objek yang lebih sederhana. Aplikasi-aplikasi berbasis java umumnya dikompilasi ke dalam pcode (bytecode) dan dapat dijalankan pada berbagai Mesin Virtual Java (JVM). Java merupakan bahasa pemrograman yang bersifat umum/non-spesifik (general purpose).

Paradigma OOP menyelesaikan masalah dengan merepresentasikan masalah ke model objek. Contoh Pemisalan Objek dalam OOP.

\subsection{Web Service}

Web service adalah aplikasi sekumpulan data (database), perangkat lunak (software) atau bagian dari perangkat lunak yang dapat diakses secara remote oleh berbagai piranti dengan sebuah perantara tertentu. Secara umum, web service dapat diidentifikasikan dengan menggunakan URL seperti hanya web pada umumnya. Namun yang membedakan web service dengan web pada umumnya adalah interaksi yang diberikan oleh web service. Berbeda dengan URL web pada umumnya, URL web service hanya menggandung kumpulan informasi, perintah, konfigurasi atau sintaks yang berguna membangun sebuah fungsi-fungsi tertentu dari aplikasi.

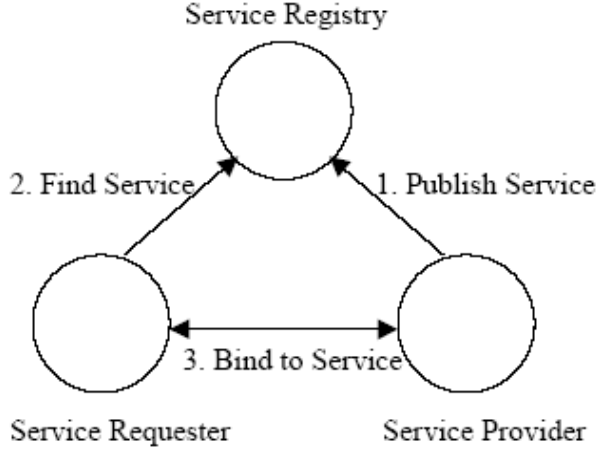

Gambar 2. Komponen Web Service

Pada Gambar 2 terdapat tiga komponen yang membuat web service berjalan. Ketiga komponen itu adalah: (a) Service provider, merupakan pemilik Web service yang berfungsi menyediakan kumpulan operasi dari Web service. (b) Service requestor, merupakan aplikasi yang bertindak sebagai klien dari Web service yang mencari dan memulai interaksi terhadap layanan yang disediakan. (c) Service registry, merupakan tempat dimana Service provider mempublikasikan layanannya. Pada arsitektur Web service, Service registry bersifat optional. Teknologi web service memungkinkan kita dapat menghubungkan berbagai jenis software yang memiliki platform dan sistem operasi yang berbeda.

\subsection{Firebase Cloud System ( FCM )}

FCM adalah sebuah layanan yang digunakan untuk melakukan pemberitahuan (notifications) pada aplikasi berbasis Android, iOS maupun aplikasi web. Dahulunya Firebase Cloud Messaging ini bernama Google Cloud Messaging atau GCM, namun sekarang sudah berubah dan menjadi lebih besar di Firebase. Langkah utama untuk mengimplementasikan FCM di Android adalah membuat project di Firebase dan meng integrasikannya dengan aplikasi Android.

Langkah langkah yang diperlukan adalah :

1. Membuat akun atau project console di Firebase Console, Lalu Create New Project atau buatlah project baru, beri nama sesuai keperluan Anda.

2. Setelah masuk dashboard, lalu carilah tombol Add Firebase to yout Android app dan ikuti saja langkahnya (masukan nama namespace dari aplikasi anda, lalu generate dan download file confignya (google-services.json).

3. Letakan file google-services.json tersebut di folder app/ dari project Anda.

4. Jangan lupa tambahkan dependensi pada gradle, lalu sync project anda.

sejauh ini ada dua metode cara kirim notifikasi. Metode pertama adalah paling simple, mengirim melalui halaman console firebase. Secara sederhana, kita login ke Console Firebase, lalu kita mengirimkan pesan notif melalui fitur yang sudah 
tersedia disana. Metode kedua adalah dengan dengan membuat server sebagai pengirim pesan, bahasa pemrogramannya bisa menggunakan php, go lang, phyton, java ataupun bahasa alien lainnya.

\subsection{Metode Penelitian}

Langkah pengembangan aplikasi gerakan nasi bungkus ini dilakukan dengan metode sekuensial linier atau yang sering disebut model air terjun ( waterfall) yang meliputi aktivitas (1) rekayasa pemodelan system, (2) analisis kebutuhan. (3) Desain. (4)Pengkodean. (5) Pengujian dan (6) Pemeliharaan. penelitian ini difokuskan pada tahapan desain dan pengkodean dengan menerapkan teknologi web service dan push notifikasi.

\subsection{Hasil dan Pembahasan}

\subsection{Pemodelan Sistem Hasil Analisis Kebutuhan}

Tahapan pemodelan ditetapkan dengan menggunakan notasi use case diagram untuk menggambarkan analisis kebutuhan sistem berdasarkan hasil komunikasi dengan pengguna. Sedangkan notasi yang untuk menggambar-kan elemen elemen aplikasi pada tahap desain dengan menggunakan diagram arsitektural dimana masing masing elemen dibuat activity diagram untuk menjelaskan detail aktivitas masing masing elemen.

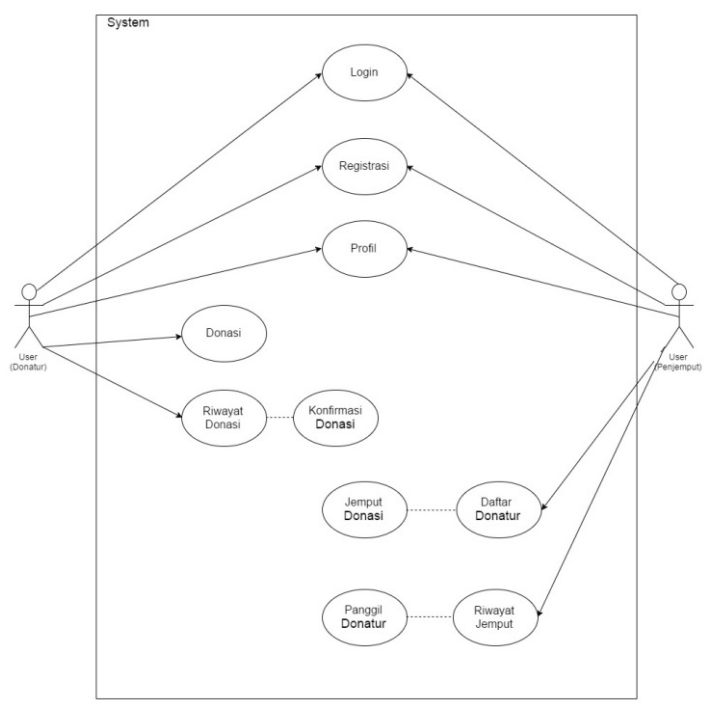

Gambar 3. Use Case Diagram Ganasbung

Setelah melakukan analisis kebutuhan, ditentukan bahwasannya aplikasi Komunitas Gerakan Nasi Bungkus Jember ini memerlukan dua mode, yaitu mode donatur dan mode penjemput. Hal ini dilakukan agar pada aplikasi ini, pengguna dapat menjadi donatur maupun penjemput donasi milik pengguna lain. Pada mode donatur, pengguna dapat melakukan donasi, melihat riwayat donasi yang telah dilakukan, dan juga dapat melakukan konfirmasi donasi bahwa donasinya, telah dijemput oleh pengguna lain. Sedangkan pada mode penjemput, pengguna dapat melihat daftar donatur yang melakukan donasi, menjemput donasi dari pengguna lain, dan juga dapat melihat riwayat penjemputan yang telah dilakukan, serta memanggil nomor telepon donatur. Berikut rancangan sistem yang penulis gambarkan dengan menggunakan use case diagram yang terlihat pada Gambar 3 dan penjelasannya pada Tabel 1 .

Tabel 1. Penjelasan Use Case Diagram Ganasbung

\begin{tabular}{|c|c|c|c|}
\hline \multirow[b]{2}{*}{ No } & \multirow[b]{2}{*}{ Use Case } & \multicolumn{2}{|c|}{ Aktor } \\
\hline & & $\begin{array}{c}\text { User } \\
\text { (Donatur) }\end{array}$ & $\begin{array}{c}\text { User } \\
\text { (Penjemput) }\end{array}$ \\
\hline 1 & Register & \multicolumn{2}{|c|}{ Melakukan registrasi akun } \\
\hline 2 & Login & \multicolumn{2}{|c|}{$\begin{array}{l}\text { Memasukkan akun yang } \\
\text { telah di registrasi }\end{array}$} \\
\hline 3 & Profil & \multicolumn{2}{|c|}{ Melihat informasi akun } \\
\hline 4 & Donasi & $\begin{array}{l}\text { Melakukan } \\
\text { donasi }\end{array}$ & \\
\hline 5 & $\begin{array}{l}\text { Riwayat } \\
\text { Donasi }\end{array}$ & $\begin{array}{l}\text { Melihat } \\
\text { riwayat } \\
\text { donasi yang } \\
\text { telah } \\
\text { dilakukan } \\
\end{array}$ & \\
\hline 6 & $\begin{array}{l}\text { Konfirmasi } \\
\text { Donasi }\end{array}$ & $\begin{array}{l}\text { Melakukan } \\
\text { konfirmasi } \\
\text { bahwa } \\
\text { donasinya } \\
\text { telah } \\
\text { dijemput } \\
\text { oleh } \\
\text { pengguna } \\
\text { lain }\end{array}$ & \\
\hline 7 & $\begin{array}{l}\text { Daftar } \\
\text { Donatur }\end{array}$ & & $\begin{array}{l}\text { Memilih } \\
\text { donasi yang } \\
\text { akan dijemput }\end{array}$ \\
\hline 8 & $\begin{array}{l}\text { Jemput } \\
\text { Donasi }\end{array}$ & & $\begin{array}{l}\text { Melakukan } \\
\text { penjemputan } \\
\text { donasi }\end{array}$ \\
\hline 9 & $\begin{array}{l}\text { Riwayat } \\
\text { Penjemputan }\end{array}$ & & $\begin{array}{l}\text { Melihat } \\
\text { riwayat } \\
\text { penjemputan } \\
\text { yang telah } \\
\text { dilakukan }\end{array}$ \\
\hline 10 & $\begin{array}{l}\text { Panggil } \\
\text { Donatur }\end{array}$ & & $\begin{array}{l}\text { Memanggil } \\
\text { nomor } \\
\text { telepon } \\
\text { donatur yang } \\
\text { tertera }\end{array}$ \\
\hline
\end{tabular}

Berdasarkan hasil pemodelan sistem, penulis selanjutnya merancang desain arsitektural untuk menjabarkan elemen-elemen dalam aplikasi ini. Berikut adalah desain arsitektural dari "Aplikasi Donatur Komunitas Gerakan Nasi Bungkus Jember Berbasis Android": 


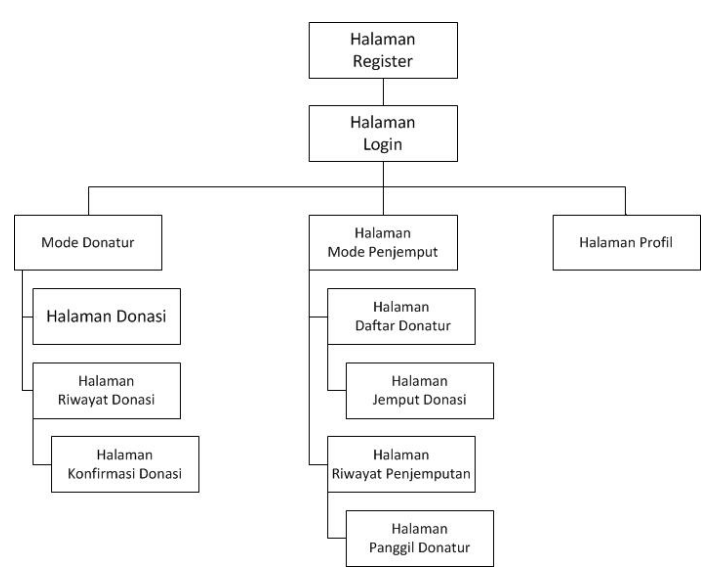

Gambar 4. Desain Arsitektural Ganasbung

Dari desain arsitektural tersebut dibuat activity diagram untuk menjelaskan segala aktivitas yang terjadi pada aplikasi ini, dan juga menjelaskan bagaimana setiap elemen yang ada saling berkesinambungan satu sama lain. Berikut adalah salah satu activity diagram yang dibuat untuk menjelaskan aktifitas sistem

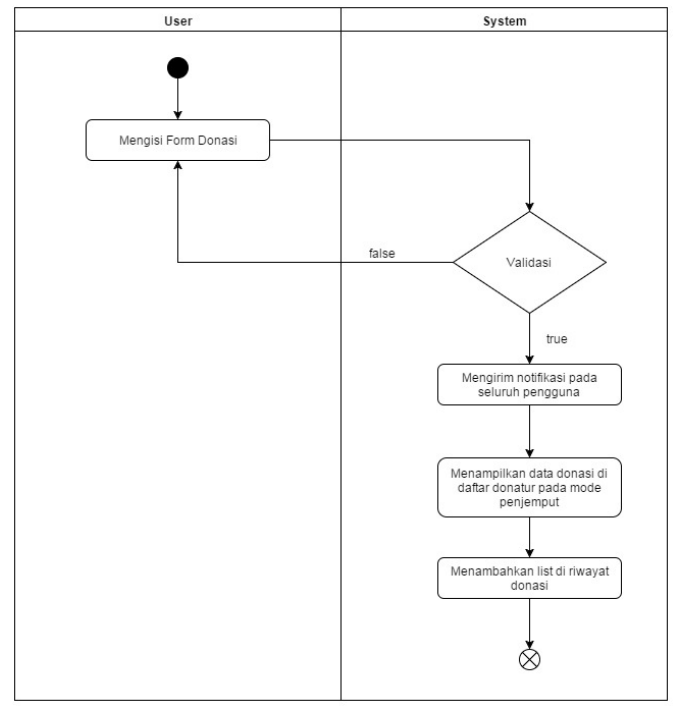

Gambar 5. Activity Diagram Donasi

User melakukan donasi di halaman donasi pada mode donatur. User sebelumnya perlu mengisi form donasi, yaitu tanggal dan waktu penjemputan, alamat penjemputan, dan jumlah donasi dari masing-masing jenis donasi. Setelah selesai user selanjutnya menekan tombol donasi, lalu sistem akan memvalidasi data donasi. Sebelum memproses donasi, sistem terlebih dahulu memastikan bahwa data yang dibutuhkan telah diisi dengan benar, jika telah dinyatakan valid sistem akan menyebarkan notifikasi kepada seluruh penggguna aplikasi dan juga akan menampilkan data donasi yang telah dimasukkan oleh donatur pada mode penjemput dan riwayat donasi

\subsection{Desain Aplikasi}

Pada tahap ini, dibuat desain tampilan untuk setiap elemen-elemen aplikasi yang telah dijelaskan pada tahap desain arsitektural. Ada beberapa tampilan yang perlu penulis desain, yaitu halaman register, halaman login, serta halaman profil. Pada mode donatur, penulis perlu membuat desain tampilan dari halaman donasi, halaman riwayat donasi dan, halaman konfirmasi donasi, sedangkan pada mode penjemput, tampilan yang perlu penulis desain adalah halaman daftar donatur, halaman jemput donasi, halaman riwayat penjemputan dan halaman panggil donatur. Penulis juga perlu mendesain sebuah navigation bar yang berfungsi memudahkan pengguna dalam berpindah dari mode donatur ke mode penjemput.

\subsection{Tahap Implementasi}

Tahap implementasi atau tahap pengkodean dimulai dengan membuat database yang sebelumnya telah didesain berdasarkan kebutuhan pengguna.

Didalam perancangan aplikasi ini membutuhkan 3 tabel dalam sebuah database. Tiga tabel tersebut digunakan untuk fungsi yang berbeda, yaitu tabel user untuk menyimpan data tentang informasi akun masing-masing pengguna, tabel donatur untuk menyimpan data tentang setiap donasi yang dilakukan oleh pengguna, dan tabel penjemput untuk menyimpan data tentang setiap penjemputan donasi yang dilakukan oleh pengguna. Gambar 6 merupakan gambaran relasi antar tabel dan rancangan setiap tabel yang ada pada database aplikasi ini:

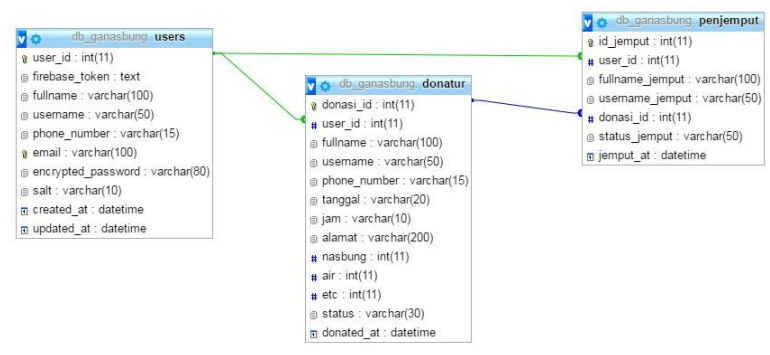

Gambar 6. Relasional Database Ganasbung

Dari sisi server pada masing msing tabel dikembangkan file web service yang diperlukan untuk melayani pengelolaan data yang diminta oleh aplikasi android. Adapun file php untuk web service sebagai berikut: 


\begin{tabular}{|c|c|c|}
\hline Dinclude & 14/02/2017 16:19 & File folder \\
\hline [] login.php & 01/03/2017 17:07 & PHP File \\
\hline register.php & 01/03/2017 16:36 & PHP File \\
\hline Config.php & $18 / 01 / 201714: 52$ & PHP File \\
\hline DB_Connect.php & 17/09/201510:29 & PHP File \\
\hline DB_Functions_User.php & 02/03/2017 6:41 & PHP File \\
\hline \multicolumn{3}{|c|}{ File web service login dan akun } \\
\hline addDonatur.php & 08/03/2017 14:21 & PHP File \\
\hline dbConnect.php & 16/02/2017 17:13 & PHP File \\
\hline getAllDonatur.php & 17/02/2017 18:40 & PHP File \\
\hline$\square$ getDonatur.php & 17/02/2017 20:09 & PHP File \\
\hline getRiwayatDonasi.php & 27/02/2017 16:12 & PHP File \\
\hline konfirmDonasi.php & 24/02/2017 17:18 & PHP File \\
\hline upd & $27 / 02 / 201716: 09$ & PHP File \\
\hline
\end{tabular}

File Web service pemberian donasi
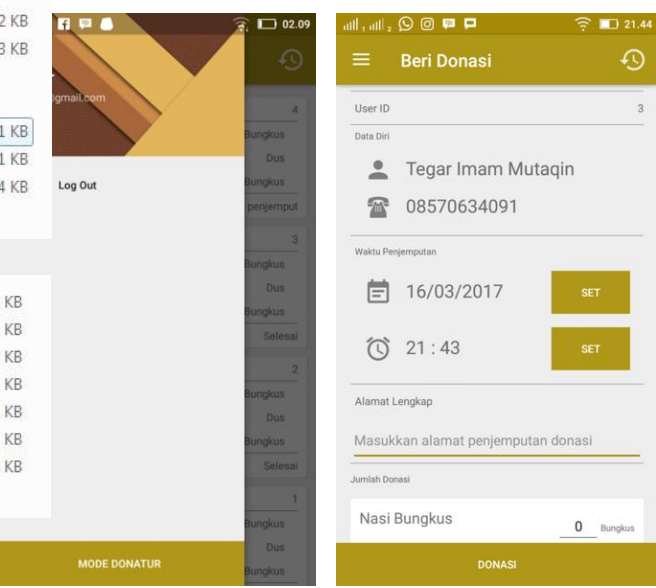

\begin{tabular}{|lll|}
\hline$\square$ addPenjemput.php & $27 / 02 / 201716: 22$ & PHP Fil \\
\hline$\square$ dbConnect.php & $16 / 02 / 201717: 13$ & PHP Fil \\
\hline getPenjemput.php & $26 / 02 / 20175: 55$ & PHP Fil \\
$\square$ getRiwayatemput.php & $27 / 02 / 201717: 06$ & PHP Fil \\
\hline updatePenjemput.php & $27 / 02 / 201716: 51$ & PHP Fil
\end{tabular}

File web service penjemputan donasi

file web service tersebut dapat diuji melalui web dengan instruksi URL yang sesuai dengan skema web servicenya. Sehingga proses penambahan, perubahan dan penghapusan data serta pemilihan data. Proses pengembangan web service merupakan proses yang terpisah dengan pengembangan aplikasi android. Format data yang dikirim maupun diterima adalah format JSON dan sinkronisasi web service Berikut gambaran rangkuman hasil implementasi aplikasi gerakan nasi bungkus

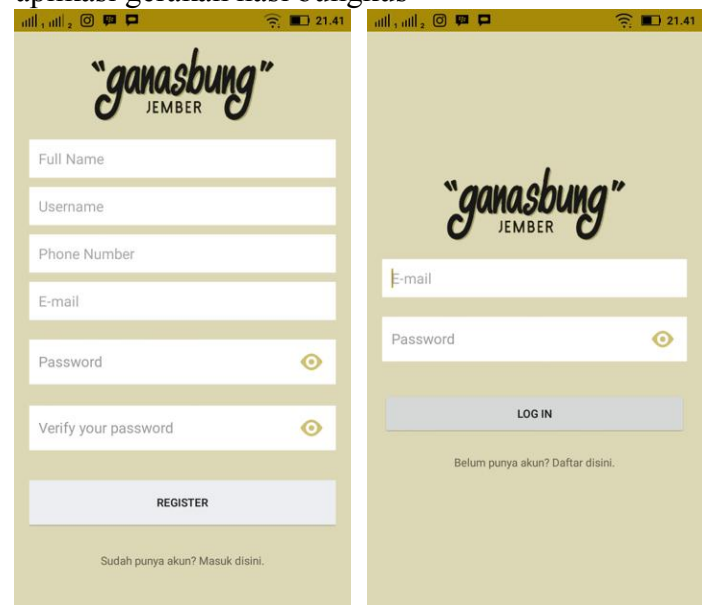

Gambar 6. Tampilan Halaman Registrasi Dan Login
Gambar 7. Tampilan Halaman Navigasi Dan Profil

$$
2 \mathrm{~KB}
$$

$1 \mathrm{~KB}$
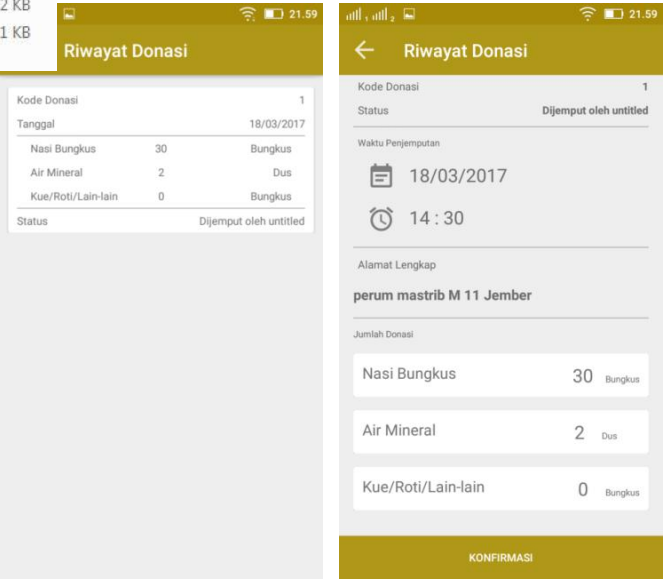

Gambar 8. Tampilan Riwayat Dan Profil Donasi

Implementasi obyek program dijelaskan pada Tabel 2 berupa file class java yang digunakan dan dikembangkan berserta penjelasan fungsi masing masing file.

Tabel 2. Kelas Jawa Aplikasi Ganasbung

\begin{tabular}{|l|l|}
\hline Java Class Name & Description \\
\hline AppConfig & $\begin{array}{l}\text { Class yang } \\
\text { mendeklarasikan url } \\
\text { server dan public string } \\
\text { untuk mendapatkan } \\
\text { JSON Object }\end{array}$ \\
\hline AppController & $\begin{array}{l}\text { Class yang harus } \\
\text { dieksekusi ketika aplikasi } \\
\text { digunakan. Class ini } \\
\text { menginisialisasi semua } \\
\text { volley core object }\end{array}$ \\
\hline SessionManager & $\begin{array}{l}\text { Class yang menyimpan } \\
\text { data user (fullname, } \\
\text { username, phone number, } \\
\text { email) ketika login. }\end{array}$ \\
\hline SQLiteHandler & Class yang meng-handle \\
\hline
\end{tabular}


Volume 4, Edisi 2, Februari 2018

\begin{tabular}{|c|c|c|c|}
\hline Java Class Name & Description & \multirow{3}{*}{\multicolumn{2}{|c|}{$\begin{array}{l}\text { diberikan kepada seluruh pengguna aplikasi } \\
\text { sehingga seluruh pengguna mengetahui ketika } \\
\text { ada pengguna lain yang memberikan donasi } \\
\text { serta agar dapat segera memeriksa donasi } \\
\text { tersebut pada mode penjemput dan melakukan } \\
\text { penjemputan donasi. }\end{array}$}} \\
\hline & $\begin{array}{l}\text { dalam menyimpanan data } \\
\text { user (fullname, username, } \\
\text { phone number, email) ke } \\
\text { SQLite Database }\end{array}$ & & \\
\hline IdSharedPreferences & $\begin{array}{l}\text { Class yang menyimpan id } \\
\text { user }\end{array}$ & & \\
\hline RequestHandler & $\begin{array}{l}\text { Class yang menghandle } \\
\text { request ke server }\end{array}$ & \multirow{8}{*}{\multicolumn{2}{|c|}{$\begin{array}{l}\text { - Notifikasi kedua adalah ketika seorang } \\
\text { pengguna melakukan penjemputan donasi yang } \\
\text { telah diberikan oleh pengguna lain, notifikasi ini } \\
\text { diberikan kepada pengguna yang donasinya akan } \\
\text { dijemput oleh pengguna lain sehingga pengguna } \\
\text { yang memberikan donasi tersebut dapat } \\
\text { mengetahui bahwa donasi yang diberikan akan } \\
\text { dijemput oleh pengguna lain. } \\
\text { Dalam tahap pembuatan servis notifikasi, pengguna } \\
\text { menggunakan Firebase Messaging Cloud yang } \\
\text { menggunakan unique token sebagai parameter } \\
\text { pengiriman notifikasi. Unique token ini didapatkan } \\
\text { oleh pengguna ketika menginstall aplikasi. Tahap } \\
\text { pertama dalam pembuatan servis notifikasi dengan } \\
\text { menggunakan Firebase Cloud Messaging adalah } \\
\text { mengintegrasikan projek android studio dengan } \\
\text { Firebase seperti yang dijelaskan pada dokumentasi } \\
\text { resmi dari firebase, } \\
\text { https://firebase.google.com /docs/android/setup. } \\
\text { Setelah projek android studio diintegrasikan dengan } \\
\text { Firebase Cloud Messagging, penulis selanjutnya } \\
\text { menambahkan beberapa java class pada proyek } \\
\text { android studio. Tabel } 3 \text { adalah daftar class java yang } \\
\text { ditambahkan beserta penjelasan fungsi dari masing- } \\
\text { masing class: } \\
\text { Tabel 3. Kelas Jawa Notifikasi Ganasbung }\end{array}$}} \\
\hline RegisterActivity & $\begin{array}{l}\text { Class yang memproses } \\
\text { data ketika user } \\
\text { melakukan registrasi }\end{array}$ & & \\
\hline LoginActivity & $\begin{array}{l}\text { Class yang memproses } \\
\text { data ketika user } \\
\text { melakukan login }\end{array}$ & & \\
\hline ProfilActivity & $\begin{array}{l}\text { Class untuk menampilkan } \\
\text { data user (fullname, } \\
\text { username, phone number, } \\
\text { email) }\end{array}$ & & \\
\hline ModeDonaturActivity & $\begin{array}{l}\text { Class untuk memproses } \\
\text { pengguna yang ingin } \\
\text { berdonasi. }\end{array}$ & & \\
\hline ModeJemputActivity & $\begin{array}{l}\text { Class yang memproses } \\
\text { pengguna ketika ingin } \\
\text { menjemput donasi dari } \\
\text { pengguna lain }\end{array}$ & & \\
\hline RiwayatDonasiActivity & $\begin{array}{l}\text { Class yang menghandle } \\
\text { catatan pengguna yang } \\
\text { telah melakukan donasi. }\end{array}$ & & \\
\hline \multirow[t]{4}{*}{ DetailDonasiActivity } & \multirow{4}{*}{$\begin{array}{l}\text { Class yang menampilkan } \\
\text { detail masing-masing } \\
\text { donasi dari daftar riwayat } \\
\text { donasi. Class ini juga } \\
\text { dapat memproses } \\
\text { pengguna yang ingin } \\
\text { mengkonfimasi donasi } \\
\text { bahwa donasi telah } \\
\text { dijemput oleh pengguna } \\
\text { lain. }\end{array}$} & & \\
\hline & & Java Class Name & Description \\
\hline & & FirebaseToken & $\begin{array}{l}\text { Class yang digunakan } \\
\text { untuk mendapatkan } \\
\text { unique token ketika } \\
\text { pengguna menginstall } \\
\text { aplikasi }\end{array}$ \\
\hline & & TokenSharedPrefManager & Class untuk \\
\hline \multirow[t]{2}{*}{ RiwayatJemputActivity } & \multirow{2}{*}{$\begin{array}{l}\text { Class yang menghandle } \\
\text { catatan pengguna yang } \\
\text { telah melakukan } \\
\text { penjemputan donasi milik } \\
\text { pengguna lain }\end{array}$} & & $\begin{array}{l}\text { menyimpan token yang } \\
\text { telah didapatkan }\end{array}$ \\
\hline & & FirebaseMessages & $\begin{array}{l}\text { Class yang digunakan } \\
\text { untuk menerima } \\
\text { notifikasi yang }\end{array}$ \\
\hline \multirow[t]{3}{*}{ DetailJemputActivity } & \multirow{3}{*}{$\begin{array}{l}\text { Class yang menampilkan } \\
\text { detail masing-masing } \\
\text { penjemputan dari daftar } \\
\text { riwayat penjemputan. } \\
\text { Class ini juga dapat } \\
\text { memproses pengguna } \\
\text { yang ingin memanggil } \\
\text { donatur yang donasinya } \\
\text { akan dijemput oleh } \\
\text { pengguna }\end{array}$} & & dikirimkan \\
\hline & & MyNotificationManager & $\begin{array}{l}\text { Class yang digunakan } \\
\text { untuk menampilkan } \\
\text { notifikasi yang telah } \\
\text { diterima }\end{array}$ \\
\hline & & & \\
\hline
\end{tabular}

\subsection{Pembuatan notifikasi}

Terdapat dua buah notifikasi dengan dua kondisi pengiriman dan pesan yang berbeda.

- Notifikasi pertama adalah ketika seorang pengguna memberikan donasi, notifikasi ini 
Selain kelas java untuk proses integrasi notifikasi diperlukan juga file php untuk web service pengirim notifikasi. Berikut adalah daftar file php yang ditambahkan pada web service.

$\square$ Config.php
$\square$ DbConnect.php
$\square$ DbOperation.php
$\square$ Firebase.php
$\square$ getAllDevices.php
Push.php
$\square$ sendMultiplePush.php
$\square$ sendSinglePush.php

https://www.simplifiedcoding.net/androidmysql-tutorial-to-perform-basic-crudoperation/

Khan, Belal, (2016), Firebase Cloud Messaging for 1 кв Android Using Php And Mysql. 1 Kв https://www.simplifiedcoding.net/firebase-

$2 \mathrm{~KB}$ cloud-messaging-android/

Kadir, Abdul, (2014), From Zero To A Pro: 1 кв Pemrograman Aplikasi Android, Jakarta. Andi ${ }_{2 \mathrm{~KB}} \mathrm{~KB}$ Publisher.

Hasil implementasi notifikasi

Setelah itu dilakukan pengujian terhadap servis notifikasi yang telah dibuat. Hal ini dilakukan agar dapat memastikan bahwa aplikasi yang telah dibuat dapat mengirim dan menerima notifikasi. Gambar 10 ini adalah hasil pengujian servis notifikasi yang telah dibuat

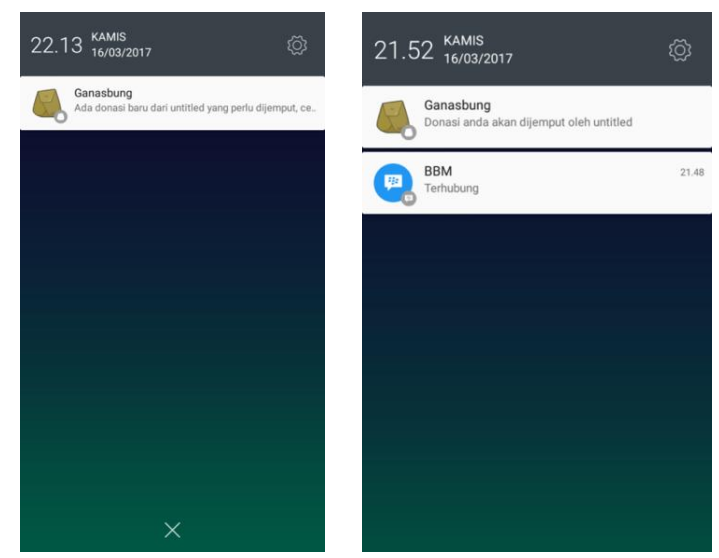

Gambar 9. Tampilan Notifikasi Pemberian Dan Penjemputan Donasi

\section{Kesimpulan}

Beberapa hal yang dapat disimpulkan dari proses penerapan web service dan push notifikasi ini adalah :

(1) Proses komunikasi data antara server dan aplikasi android menggunakan format web service dapat dilakukan sebagai jembatan perbedaan platform bahasa pemrograman

(2) Penggunaan fitur notifikasi secara sistem dapat membantu proses validasi data bagi pengguna.

(3) Gerakan nasi bungkus jember merasakan manfaat secara langsung dengan adanya aplikasi ini.

\section{Daftar Pustaka:}

Tamada, Ravi, (2016), Android Login And Register With Php, Mysql, And SQLite,

http://www.androidhive.info/2012/01/androidlogin-and-registration-with-php-mysql-andsqlite/

Khan, Belal, (2015), Android Mysql Tutorial To
Perform
Basic
CRUD Operation. 